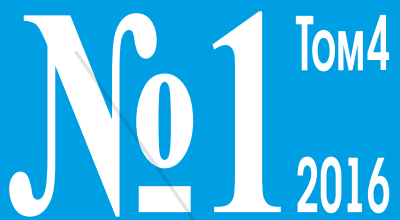

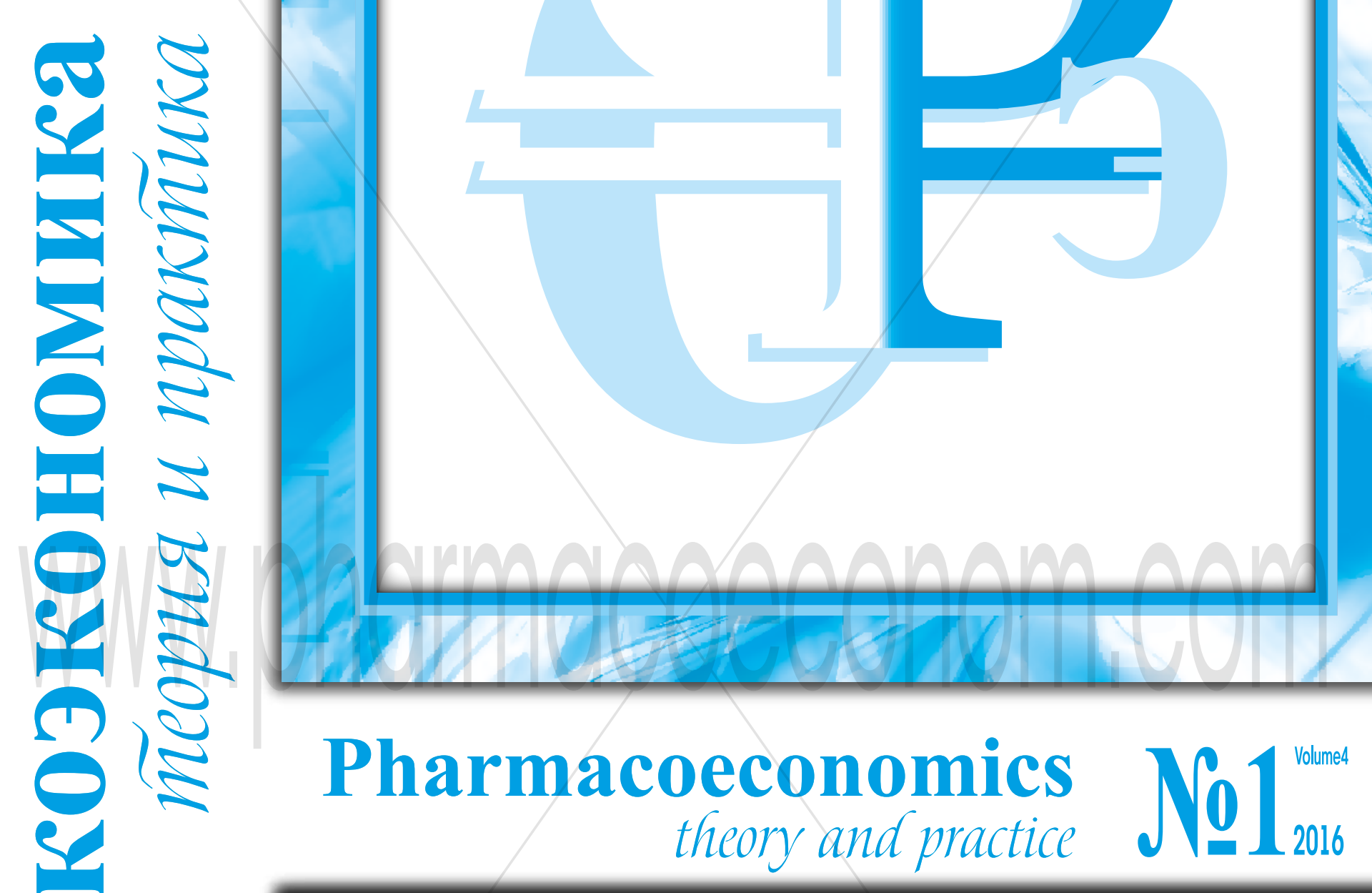

$\square$ МЕТОДОЛОГИЧЕСКИЕ ОСНОВЫ ФАРМАКОЭКОНОМИЧЕСКОГО МОДЕЛИРОВАНИЯ

$\square$ РЕЗУЛЬТАТЫ РОССИЙСКИХ ФАРМАКОЭКОНОМИЧЕСКИХ ИССЛЕДОВАНИЙ

口 МАТЕРИАЛЫ Х НАЦИОНАЛЬНОГО КОНГРЕССА С МЕЖДУНАРОДНЫМ УЧАСТИЕМ «РАЗВИТИЕ ФАРМАКОЭКОНОМИКИ И ФАРМАКОЭПИДЕМИОЛОГИИ В РОССИЙСКОЙ ФЕДЕРАЦИИ» 4-5 апреля 2016 г., г. Нижний Новгород 


\title{
ФАРМАКОЭКОНОМИЧЕСКИЙ АНАЛИЗ ЛЕКАРСТВЕННОГО ПРЕПАРАТА МОНОФЕР (ЖЕЛЕЗА ІІІ - ГИДРОКСИД ОЛИГОИЗОМАЛЬТОЗАТ) В ЛЕЧЕНИИ ЖЕЛЕЗОДЕФИЦИТНОЙ АНЕМИИ
}

\author{
Куликов А.Ю. ${ }^{1}$, Скрипник А.P. ${ }^{2}$ \\ ${ }^{1}$ ГБОУ ВПО «Первый МГМУ им. И.М. Сеченова» \\ ${ }^{2}$ Финансовый университет при Правительстве Российской Федерации
}

\begin{abstract}
Pезюме:
Среди наиболее распространенных заболеваний железодесицитная анемия занимает первое место из всех диагностируемых анемий она составляет порядка 70-90\%. В Российской Федерации железодесицитная анемия выявляется у 6-30\% населения, что приводит к необходимым затратам по ее коррекции. Целью данного исследования являлся сравнительный фрармакоэкономический анализ лекарственных препаратов Монофер (Железа III - гидроксид олигоизомальтозат) в сравнении с ЛП Феринжект (Железа III - карбоксимальтозат) в лечении железодесицитной анемии в условиях российского здравоохранения. В результате анализа затрат рассчитана стоимость лечения одного пациента, которая составила 10717 руб. для терапии ЛП Монофер и 14217 руб. для терапии ЛП Феринжект. По результатам анализа «затраты-эффрективность» были выявлены коэфффициенты CER, которые составили 11401 руб. и 13670 руб. за увеличение уровня гемоглобина на 1 единицу (г/дл) для терапии ЛП Монофер и ЛП Феринжект соответственно. Анализ "влияния на бюджет» показал, что использование терапии ЛП Монофер для одного пациента в сравнении с терапией ЛП Феринжект позволяет сэкономить денежные средства в размере 3500 руб. Проведенный анализ чувствительности показал, что при увеличении стоимости ЛП Монофер на 10\% и уменьшении стоимости ЛП Феринжект на 10\%, результаты анализов «затраты-эфффективность» и «влияния на бюджет» остаются устойчивыми.

Ключевые слова: анализ эфрфективности, анализ затрат, анализ «затраты-эфффективность», анализ «влияния на бюджет», анализ чувствительности, железодефицитная анемия, фрармакоэкономика, клинико-экономический анализ.
\end{abstract}

\section{Введение}

Анемия представляет собой снижение концентрации гемоглобина в единице объема крови, которая часто сопровождается снижением концентрации эритроцитов в единице объема крови. В результате несоответствия поступления и потребления железа, возникает десицит железа и как следствие ослабление эритропоэза, что является признаком железодесицитной анемии наряду со снижением наполнения гемоглобина железом с последующим уменьшением содержания гемоглобина в эритроците [12].

Среди наиболее распространенных заболеваний железодефицитная анемия занимает первое место. Среди всех диагностируемых анемий она составляет 70-90\%. В мире железодесицитной анемией страдают около 700 млн. человек. В России железодесиццитная анемия выявляется у $6-30 \%$ населения [10].
Развитие анемии при ХПН обусловлено нарушением выработки эритропоэтина (ЭПО) в почках. Тяжесть анемии коррелирует со степенью нарушения фрункции почек. В патогенезе анемии играют роль дефицит железа и повышенный уровень воспалительных цитокинов [20].

По своим характеристикам анемия при ХБП является гипорегенераторной, нормохромной, нормоцитарной, что соответствует гипопластической анемии, а также анемии хронических болезней [20].

В настоящее время на рынке существует большой спектр внутривенных и пероральных препаратов железа. Побочные эфффекты пероральных препаратов двухвалентного железа включают в основном диспептические расстройства и боль в животе. Однако препараты трехвалентного железа практически не вызывают диспептических расстройств и боли в животе и могут применяться с пищей. Парентеральное назначение препаратов железа позволяет быстро доставить их к месту назначения - в костный мозг [9].

Препараты железа, присутствующие на рынке рассматриваются как одинаково эффективные, но отличающиеся по содержанию свободного диализного железа, несвязанного железа как действием внешних фракторов (железо растворимое в кислоте), также как и в исследованиях in vitro в человеческой плазме. Это может объясняться целым рядом побочных эфрфектов наночастиц различных препаратов железа. Поэтому препараты железа не могут быть легко заменяемы и в каждом случае необходим индивидуальный подход врача к пациенту до введения препарата, и для некоторых препаратов необходимо проведение тест дозы для исключения побочных реакций [5].

Monofer ${ }^{\circledast}$ (Железа III - гидроксид олигоизомальтозат) - новейший внутривенный железосодержащий препарат с очень низким иммуногенным потенциалом и очень низким содержанием лабильного и свободного железа.

Запатентованная химическая структура IronMatrix препарата Монофер гарантирует стабильность комплекса железа и контролируемое высвобождение в организме [7]. По сравнению с существующими внутривенными препаратами железа, Монофер содержит сильно связанное железо в железо-углеводной матрице, с очень низким содержанием лабильного и свободного железа. Это дает возможность Моноферу, как единственному среди всех препаратов внутривенного железа, быть назначенным в виде быстрых высокодозных инфузий в дозе 1000-1500 мг, 20мг/кг без ограничения максимального количества железа одной инсрузией. Кроме этого, в отличие от других препаратов железа для внутривенного введения, Монофер можно вводить без тестовой дозы. Это позволяет гибко дозировать, в том числе и высокие дозы, и добиваться быстрого насыщения железом, предлагая удобное однократное посеще- 
ние для терапии железом широкого спектра пациентов [5].

Применение Монофера у пациентов с хронической болезнью почек как на додиализной, так и на диализной стадиях повторными болюсами или инфузией общей дозы представляется безопасным, хорошо переносимым, с минимальной иммуногенностью и несротоксичностью, высокой эффрективностью, значимым улучшением качества жизни, и обеспечивающее улучшение показателей обмена железа и терапию анемии [1, 2, 3, 4, 9].

Высокий профиль безопасности препарата Монофер подтвержден клиническими исследованиями PROCEED и PROCEED EXT.

\section{Цель исследования}

Целью данного исследования являлся фрармакоэкономический анализ лекарственных препаратов ЛП Монофрер (Железа III - гидроксид олигоизомальтозат) в сравнении с ЛП Феринжект (Железа III - карбоксимальтозат).

Для достижения данной цели последовательно решались следующие задачи:

1. Информационный поиск в базах данных Medline, Cochrane, научной электронной библиотеке eLIBRARY.RU, и других источниках в сети Интернет

2. Поиск и выбор РКИ для проведения сравнительного фрармакоэкономического анализа двух схем терапии (ЛП Монофер; ЛП Феринжект) у пациентов с железодесрицитной анемией

3. Определение показателей эффрективности данных двух схем терапии на основании опубликованных данных клинических исследований

4. Анализ затрат по двум схемам терапииАнализ «затраты-эфффективность»

5. Анализа «влияния на бюджет»

6. Проведение анализа чувствительности

\section{Анализ эффективности}

Первым этапом фрармакоэкономического исследования был анализ эфффективности. Данный анализ подразумевает сбор необходимых данных об эфрфективности лекарственного средства и выбор показателя эфрфективности, удовлетворяющего условиям проводимого фрармакоэкономического исследования.

По итогам информационного поиска среди найденных публикаций не было ни одного клинического исследования, где сравнивались бы между собой напрямую ЛП Монофер и ЛП Феринжект, поэтому в каче- стве анализа эфффективности было проведено непрямое исследование, которое можно представить в виде следующей сети (рис. 1)

По итогам информационного поиска среди найденных публикаций было отобрано 2 клинических исследования, в котором производились сравнения альтернатив:

1. ЛП Монофер и сульфрат железа у пациентов с хронической почечной недостаточностью с железодефицитной анемией - исследование NDT Philip A. Kalra и соавт. [7].

2. ЛП Феринжект и сульфрат железа у пациентов с хронической почечной недостаточностью с железодесицитной анемией - исследование Wajeh Y. Qunibi и соавт. [8].

Результаты полученные в указанных исследованиях являются сопоставимыми, так как средний возраст пациентов и исходный уровень показателей гемоглобина, насыщения трансферрина и ферритина в сыворотке являются примерно одинаковыми (табл.1), что позволяет использовать их результаты в рамках непрямого сравнения.

Таблица 1. Данные клинических исследований

\begin{tabular}{|c|c|c|c|c|c|}
\hline Параметры & Феринжект & $\begin{array}{c}\text { Сульфрат } \\
\text { железа }\end{array}$ & Монофер & $\begin{array}{c}\text { Сульрат } \\
\text { железа }\end{array}$ \\
\hline $\begin{array}{c}\text { Всего } \\
\text { пациентов }\end{array}$ & 147 & 103 & 234 & 118 \\
\hline \multicolumn{5}{|c|}{ Демограсические и основные характеристики } \\
\hline $\begin{array}{c}\text { Средний } \\
\text { возраст } \\
\text { пациентов, лет }\end{array}$ & 65,4 & 66,8 & & 57,6 & 57,9 \\
\hline \multicolumn{5}{|c|}{ Показатели } \\
\hline $\begin{array}{c}\text { Гемоглобин } \\
\text { (г/дл) }\end{array}$ & 10,10 & 10,00 & 9,67 & 9,64 \\
\hline $\begin{array}{c}\text { Насыщение } \\
\text { трансферрин } \\
\text { (\%) }\end{array}$ & 15,4 & 15,8 & & 18,1 & 15,5 \\
\hline $\begin{array}{c}\text { Ферритин в } \\
\text { сыворотке (нг/ } \\
\text { мл) }\end{array}$ & 111,8 & 104,8 & 95,00 & 98,8 \\
\hline
\end{tabular}

Представленные в таблице 2 результаты анализа эфффективности указывают на сколько единиц (г/дл) увеличился уровень гемоглобина как основной критерий эффективности.

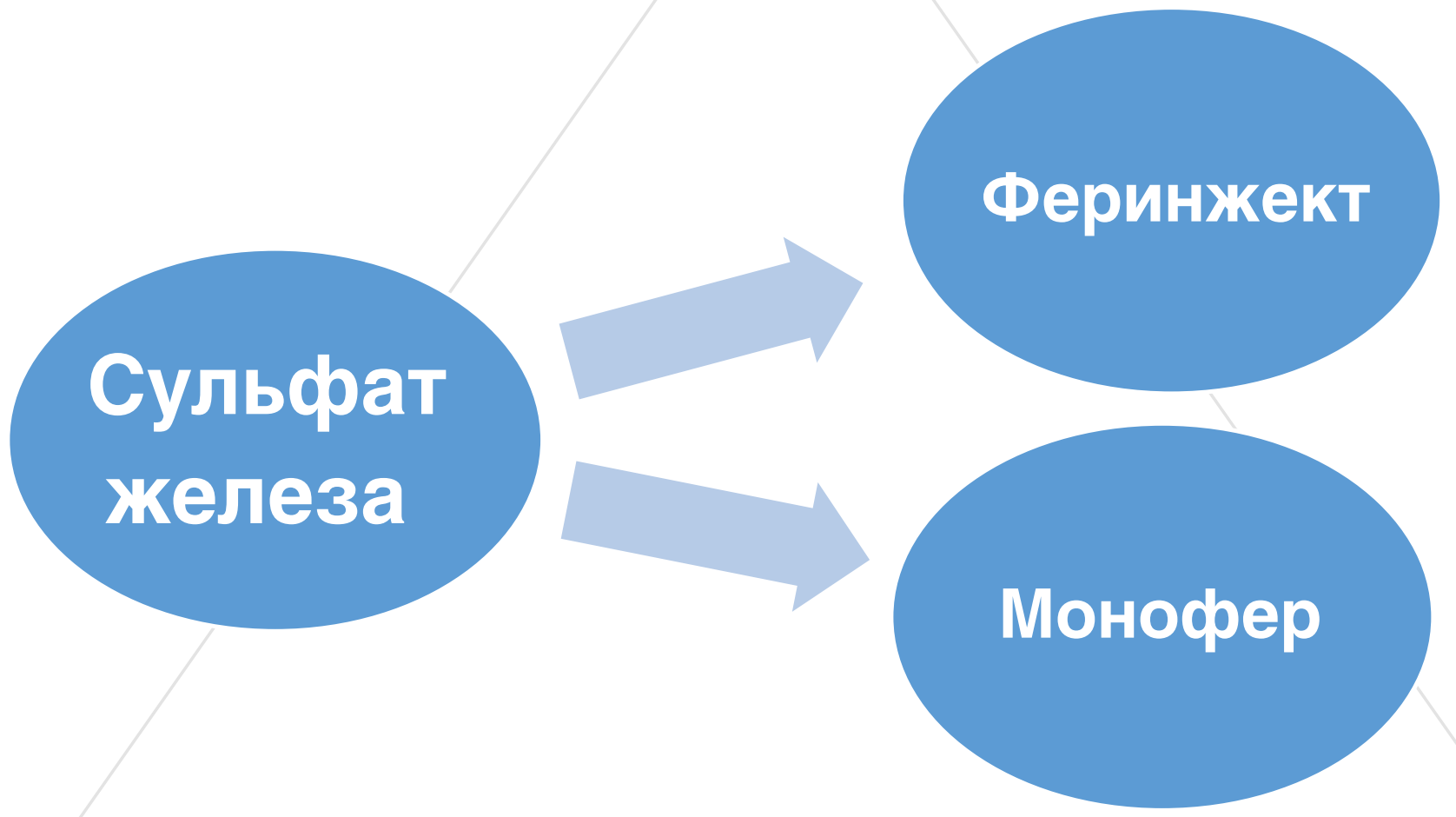

Рисунок 1. Сеть непрямого сравнения 
Таблица 2. Анализ эффективности

\begin{tabular}{|c|c|c|}
\hline \multirow{2}{*}{ Неделя } & \multicolumn{2}{|c|}{ Увеличение уровня гемоглобина (г/дл) } \\
\cline { 2 - 3 } & Монофер & Феринжект \\
\hline 2 & 0,33 & 0,35 \\
\hline 4 & 0,60 & 0,78 \\
\hline 6 & н/д & 0,94 \\
\hline 8 & 0,94 & 1,04 \\
\hline
\end{tabular}

Из представленных значений видно, что при применении схемы лечения ЛП Монофер к 8 неделе в среднем на одного пациента уровень гемоглобина повышается на 0,94 г/дл, а при применении схемы терапии ЛП Феринжект - повышается на 1,04 г/дл.

\section{Анализ затрат}

Следующим этапом проведенного фармакоэкономического исследования был анализ затрат.

При расчете прямых медицинских затрат были учтены следующие расходы, связанные с оказанием медицинской помощи:

1. Стоимость медицинских услуг согласно Приказу Минздравсоцразвития РФ «Об утверждении стандарта медицинской помощи больным железодесицитной анемией» [16].

2. Стоимость лекарственных препаратов.

3. Стоимость введения лекарственных препаратов согласно Тарифному соглашению на медицинские услуги, оказываемые по территориальной программе обязательного медицинского страхования города Москвы на 2014 год и на плановый период 2015 и 2016 годов от 25.12.2014 [18].

В используемые исследования ЛП Монофер и ЛП Феринжект были включены пациенты возрастом около 60 лет: в исследовании NDT Philip A. Kalra и соавт. пациенты с о средним возрастом 66 лет, в исследовании Wajeh Y. Qunibi и соавт. - 58 лет. Таким образом, так как средний возраст пациентов достиг пенсионного, непрямые затраты в данном фрармакоэкономическом исследовании не учитывались.

Затраты на медицинские услуги (МУ) рассчитывались с учетом данных о частоте назначения и кратности применения МУ для диагностики и лечения больного. Согласно Приказа Минздравсоцразвития РФ «0б утверждении стандарта медицинской помощи больным железодесицитной анемией» затраты на МУ составили 1141 руб. на лечение одного пациента и были одинаковы для всех схем терапии, так как данные услуги предоставляются каждому пациенту с железодесицитной анемией.

Согласно инструкции по медицинскому применению ЛП Монофер вводят однократно в размере 1000 мг; ЛП Феринжект - дважды с интервалом в 2 недели в дозировке по 500 мг.

Таким образом, затраты на ЛП Монофер составили 9081 руб., на ЛП Феринжект - 12086 руб. (табл. 3).

Таблица 3. Затраты на фармакотерапию ЛП Монофер и ЛП Феринжект

\begin{tabular}{|c|c|c|c|c|c|}
\hline & \multirow{2}{*}{ МнН } & \multirow{2}{*}{ Цикл/курс } & Доза, мг & \multicolumn{2}{|c|}{ Стоимость, руб. } \\
\cline { 5 - 6 } & & & $\begin{array}{c}\text { Однократное } \\
\text { введение }\end{array}$ & $\begin{array}{c}\text { Курсовая } \\
\text { стоимость }\end{array}$ \\
\hline 1. & Моносрер & 1 & 1000 & 9081 & 9081 \\
\hline 3. & Феринжект & 2 & 500 & 6043 & 12086 \\
\hline
\end{tabular}

Исходя из тарифов ФФОМС г. Москвы, установлено, что стоимость внутривенного введения составляет 77 руб., а средняя стоимость нахождения в дневном стационаре 418 руб. Следовательно, введение каждого из сравниваемых препаратов сопровождается дополнительными затратами на МУ. ЛП Монофер вводится однократно и затраты на его введение составят 495 руб., в то время как для ЛП Феринжект, который вводится дважды, затраты составят 990 руб.

Сложив все затраты на МУ были определены общие затраты, которые составили 10717 руб. при лечении ЛП Моносер и 14217 руб. для ЛП Феринжект на одного пациента соответственно (табл.4).
Таблица 4. Общие затраты на лечение одного пациента, руб.

\begin{tabular}{|c|c|c|c|c|}
\hline & $\begin{array}{c}\text { Основная } \\
\text { фармакотерапия }\end{array}$ & $\begin{array}{c}\text { Затраты } \\
\text { на Му }\end{array}$ & $\begin{array}{c}\text { Затраты на } \\
\text { введение }\end{array}$ & $\begin{array}{c}\text { Общие } \\
\text { затраты }\end{array}$ \\
\hline Монофер & 9081 & 1141 & 495 & 10717 \\
\hline Феринжект & 12086 & 1141 & 990 & 14217 \\
\hline
\end{tabular}

\section{Анализ «затраты-эффективность»}

На следующем этапе были определены значения коэффициентов «затраты-эффективность» (cost-effectiveness ratio - CER) при применении ЛП Монофер в сравнении с применением ЛП Феринжект по критерию повышения уровня гемоглобина на 1 единицу измеряемую в г/дл. Полученные значения CER представлены в таблице 5 .

Как видно из представленных результатов, наименьших затрат за достижение единицы гемоглобина требует схема с использованием ЛП Монофер. Значение CER для терапии ЛП Монофер составляет 11401 руб. за увеличение уровня гемоглобина на 1 г/дл, а для ЛП Феринжект 13670 руб. за увеличение уровня гемоглобина на 1 г/дл. Таким образом, использование ЛП Монофер является «затратно-эфффективным» методом лечения железодефицитной анемии с точки зрения фармакоэкономики.

Таблица 5. Результаты анализа «затраты-эффективность»

\begin{tabular}{|c|c|c|}
\hline Показатели & Монофер & Феринжект \\
\hline Затраты, руб. & 10717 & 14217 \\
\hline Эфффективность, г/дл & 0,94 & 1,04 \\
\hline Затраты-эфффективность, руб. & 11401 & 13670 \\
\hline
\end{tabular}

\section{Анализ «влияния на бюджет»}

Анализ является основополагающим в современной системе фармакоэкономической оценки. Суть анализа «влияния на бюджет» (budget impact analysis - BIA) заключается в оценке финансовых последствий применения и и частоты использования новых медицинских технологий с учётом ограниченности ресурсов конкретного ЛУ или системы здравоохранения в целом. Под новой медицинской технологией в данном случае понимается новый лекарственный препарат или новый метод лечения [27]. Данный анализ позволяет спрогнозировать влияние на бюджет здравоохранения и определить экономический эффект, который выражается либо экономией денежных средств, либо дополнительными затратами, при переходе с терапии сравнения на оцениваемую терапию. Для полноты анализа требуется учесть все виды расходов.

Таким образом, анализ «влияния на бюджет» в данном исследовании учитывал стоимость основной терапии, ЛП и введения ЛП пациентам с железодефицитной анемией.

Результаты анализа «влияния на бюджет» на курс лечения на одного пациента с железодефицитной анемией отражены в таблице 6.

Таблица 6. Результаты анализа «влияния на бюджет», руб.

\begin{tabular}{|c|c|c|c|}
\hline \multirow{2}{*}{} & \multicolumn{2}{|c|}{ Стоимость схемы лечения, руб. } & \multirow{2}{*}{ Влияние на бюджет } \\
\cline { 2 - 3 } & Монофер & Феринжект & \\
\hline $\begin{array}{c}\text { Затраты на } \\
\text { одного пациента }\end{array}$ & 10717 & 14217 & 3500 \\
& & & Экономия \\
\hline
\end{tabular}

По результатам анализа «влияния на бюджет» можно сделать вывод о том, что при переходе одного больного с железодефицитной анемией с терапии ЛП Феринжект на терапию ЛП Монофер возникает экономия денежных средств в размере 3500 руб. на одного пациента, что позволяет снизить затраты на $25 \%$.

\section{Анализ чувствительности}

По итогам анализа чувствительности из таблицы 7 видно, что результаты фармакоэкономического анализа СЕА и ВІА устойчивы при одновременном увеличении стоимости терапии ЛП Монофер и уменьшении стоимости ЛП Феринжект на 10\%, так как при изменении значений в этом диапазоне показатели данных для лечения схемой ЛП Монофер остаются меньше по отношению к показателям терапии ЛП Феринжект. 
Таблица 7. Результаты анализа чувствительности при одновременном изменении стоимости основной фармакотерапии в сравниваемых группах, руб.

\begin{tabular}{|c|c|c|c|c|}
\hline \multirow{2}{*}{$\begin{array}{c}\text { Изменение } \\
\text { цены }\end{array}$} & \multicolumn{2}{|c|}{ Монофер } & \multicolumn{2}{c|}{ Феринжект } \\
\cline { 2 - 5 } & CER & Затраты & CER & Затраты \\
\hline$+10 \%$ & 12367 & 11625 & 14832 & 15426 \\
\hline 0 & 11401 & 10717 & 13670 & 14217 \\
\hline$-10 \%$ & 10435 & 9809 & 12508 & 13009 \\
\hline
\end{tabular}

\section{Результаты}

В результате анализа затрат получена суммарная стоимость лечения пациента, которая составила 10717 руб. для терапии ЛП Монофер и 14217 руб. для терапии ЛП Феринжект.

По результатам анализа «затраты-эффективность» были выявлены коэфффициенты CER , которые составили 11401 руб. и 13670 руб. для терапии ЛП Монофер и ЛП Феринжект соответственно.

При расчете анализа «влияния на бюджет» показано, что использование терапии ЛП Монофер в сравнении с терапией ЛП Феринжект позволяет сэкономить бюджетные средства в размере 3500 руб в расчете на одного пациента.

\section{Выводы}

На основании проведенного фармакоэкономического анализа можно сделать вывод, что терапия с применением ЛП Монофер по сравнению с ЛП Феринжект при лечении железодефицитной анемии имеет клинико-экономическое преимущество за счет меньшей стоимости лечения и ведет к экономии денежных средств.

\section{Список литературы}

1. Hypert PJN, Kalra PA, Bock K, Meldal M. Iron isomaltoside 1000 : a new high dose option for parenteral iron therapy. 2012;26(March):1-12.

2. Gozzard D. When is high-dose intravenous iron repletion needed? Assessing new treatment options. Drug Des Devel Ther. 2011;5:51-60. doi:10.2147/DDDT.S15817.

3. Gupta DR, Larson DS, Thomsen LL, Coyne DW. Pharmacokinetics of Iron Isomaltoside1000 in Patients with Stage 5 Chronic Kidney Disease on Dialysis Therapy. J Drug Metab Toxicol. 2013;04(03). doi:10.4172/21577609.1000152.

4. Mace TA, Syed A, Bhandari S. Iron (III) isomaltoside 1000. Expert Rev Hematol. 2013;3(6):239-246.

5. Markus R. Jahn, Hans B. Andreasen, Sören Fütterera Thomas Nawroth, Volker Schünemann, Ute Kolb, Wolfgang Hofmeister, Manuel Muñoz, Klaus Bock, Morten Meldal, Peter Langguth Сравнительное изучение физико-химических свойств железа изомальтозата 1000 (Monofer ${ }^{\circledR}$ ), нового препарата железа для внутривенного введения, и его клиническое значение.// European Journal of Pharmaceutics and Biopharmaceutics 78(2011) - c.480-491.

6. Monofer $100 \mathrm{mg} / \mathrm{ml}$ solution for injection/infusion. Summary of Product Characteristic. Last Updated on eMC 09-Apr-2014. http://www.medicines. org.uk/emc/medicine/23669

7. Philip A. Kalra, Sunil Bhandari, Sanjiv Saxena, Dhananjai Agarwal, Georg Wirtz, Josef Kletzmayr, Lars L. Thomsen and Daniel W. Coyne A randomized trial of iron isomaltoside 1000 versus oral iron in non-dialysis-dependent chronic kidney disease patients with anaemia// Nephrol Dial Transplant. 2015 - c. 1-10.

8. Wajeh Y. Qunibi, Carlos Martinez, Mark Smith, Joseph Benjamin, Antoinette Mangione5 and Simon D. Roger A randomized controlled trial comparing intravenous ferric carboxymaltose with oral iron for treatment of iron deficiency anaemia of non-dialysis-dependent chronic kidney disease patients // Nephrol Dial Transplant (2011) 26: - c.1599-1607.

9. Wikström B, Bhandari S, Barany P, et al. Iron isomaltoside 1000: a new intravenous iron for treating iron deficiency in chronic kidney disease. $\mathrm{J}$ Nephrol. 2011;24(5):589-96. doi:10.5301/JN.2010.9999.

10. Бокарев И.Н. Анемический синдром / И.Н. Бокарев, Е.Н. Немчинов, Т.Б. Кондратьева. - М.: Практическая медицина, 2006. - 128 с.

11. Государственный реестр предельных отпускных цен [Электронный ресурс] - Режим доступа: www.grls.rosminzdrav.ru.

12 Дворецкий Л.И. Лечение железодефицитной анемии // Русский медицинский журнал. 1998. т.6. 20 - с.1312-1316.

13. Инструкция по медицинскому применению лекарственного препарата Монофер. Министерство здравоохранения и социального развития Российской Федерации. ЛП 001499-130212

14. Куликов А.Ю. Рынок медицинских услуг: особенности функционирования и развития. Калининград: Изд-во РГУ им. И. Канта, 2009. - 326 с.

15. Куликов А.Ю., Литвиненко М.М. Методологические основы моделирования при проведении фрармакоэкономических исследований: разные уровни сложности и разная ценность полученных результатов // Фармакоэкономика: теория и практика. - 2014. - Т.2, №2. - С.9-15.

16. Приказ Минздравсоцразвития РФ от 28.02.2005 N 169 «0б утверждении стандарта медицинской помощи больным железодефицитной анемией»

17. Протокол ведения больных железодефицитная анемия от 22.10.2004 г. 18. Тарифнне соглашение на медицинские услуги, оказываемые по территориальной программе обязательного медицинского страхования города Москвы на 2014 год и на плановый период 2015 и 2016 годов от 25.12.2014

19. Хабриев Р.У., Куликов А.Ю., Аринина Е.Е. Методологические основы фармакоэкономического анализа. М.: ОАО «Издательство «Медицина», 2011. - $128 \mathrm{c}$.

20. Эттингер О.А., Зеновко И.К., Гендлин Г.Е. Анемия при хронической болезни почек: роль препаратов железа// Рекомендации по ведению больных // Лечебное дело 4. - 2012 - с.38-46.

21. Ягудина Р.И., Аринина Е.Е., Бабий В.В. Анализ фракторов, влияющих на процесс принятия решения в области организации лекарственного обеспечения: теория принятия решений // Современная организация лекарственного обеспечения. - 2015. - №2 - С.19-23.

22. Ягудина Р.И., Бабий В.В. Методологические основы анализа эффективности медицинских технологий при проведении фармакоэкономических исследований // Фармакоэкономика: теория и практика. - 2015. - Т.3, №1. - С.7-11.

23. Ягудина Р.И., Куликов А.Ю., Аринина Е.Е. Фармакоэкономика в онкологии. М.: ЗАО «Шико», 2011. - 568 с.

24. Ягудина Р.И., Серпик В.Г. О возможностях совмещения анализа «влияния на бюджет» и анализа «затраты-эфффективность» - создание «3D» фармакоэкономической модели // Фармакоэкономика: теория и практика. - 2014. - Т.2, №3. - С.4-8.

25. Ягудина Р.И., Серпик В.Г., Куликов А.Ю. Фармакоэкономика для организаторов здравоохранения. Алгоритм принятия решений на основе фармакоэкономической оценки. // Фармакоэкономика: теория и практика. - 2014. - Т.2, №1. - С.5-12.

26. Ягудина Р.И., Серпик В.Г., Сороковиков И.В. Методологические основы анализа «затраты-эффеективность» // Фармакоэкономика: теория и практика. - 2014. - Т.2, №2. - С.23-26.

27. Ягудина Р.И., Серпик В.Г., Угрехелидзе Д.Т. Методологические основы анализа «влияния на бюджет» // Фармакоэкономика: теория и практика. - 2015.-Т. 3, №4-C.5-8. 